\section{Preharvest Application of Phellodendron Bark Extracts Controls Brown Rot and Maintains Quality of Peento-shaped Peach}

\author{
Xiaoyuan Feng ${ }^{1}$ \\ College of Food Science and Nutritional Engineering, China Agricultural \\ University, Beijing 100094, China; and the Institute of Forestry and \\ Pomology, Beijing Academy of Agriculture and Forestry Sciences, Jia 12 \\ Ruiwang Fen Xiangshan ST, Haidian District, Beijing 100093, China
}

\author{
Baogang Wang, Wensheng Li, and Lei Shi \\ Institute of Forestry and Pomology, Beijing Academy of Agriculture and \\ Forestry Sciences, Beijing 100093, China
}

Jiankang Cao and Weibo Jiang College of Food Science and Nutritional Engineering, China Agricultural University, Beijing 100094, China

Additional index words. enzymatic activity, firmness, Monilinia fructicola, Phellodendron chinese, Prunus persica var. platycarpa

\begin{abstract}
Preharvest application of Phellodendron bark (Phellodendron chinese Schneid) extract (PBE) on brown rot and postharvest quality of peach [Prunus persica (L.) Batsch var. platycarpa (Decne.) L.H. Bailey] was investigated. PBE at $0.8,1.6$, and $3.2 \mathrm{mg} \cdot \mathrm{mL}^{-1}$ totally inhibited conidial germination, mycelial growth, and sporulation, respectively, of Monilinia fructicola in vitro. Preharvest PBE treatment at $21.0 \mathrm{mg} \cdot \mathrm{mL}^{-1}$ at $0,30,60$, and 90 days after full bloom controlled brown rot caused by $M$. fructicola on peach fruit after harvest and reduced disease incidence and lesion diameter by $37 \%$ and $61 \%$, respectively, than those of the control $96 \mathrm{~h}$ after inoculation in in vivo experiments. The results from field experiments were consistent during a 3-year period. Fruit from PBEtreated trees showed higher activities of defense enzymes, including peroxidase, phenylalanine ammonia-lyase, chitinase, and $\beta$-1,3-glucanase, compared with those of the control during storage. PBE also delayed softening and loss of titratable acidity and inhibited flesh browning during storage. Total soluble solid contents were unaffected by treatment. The results indicate that preharvest application of PBE may be an alternative for controlling brown rot of peach fruit.
\end{abstract}

Brown rot caused by Monilinia fructicola Honey is the major postharvest disease of peaches [Prunus persica (L.) Batsch var. platycarpa (Decne.) L.H. Bailey] in China and severely limits its storage and shelf life. When weather conditions (high rainfall and humidity, warm temperatures) are favorable for disease development, postharvest losses can be as high as $80 \%$ to $90 \%$ (Hong et al., 1998). Management of postharvest brown rot of peaches often begins with preharvest disease control programs (Conway, 1987; Elmer et al., 2007; Lichou et al., 2005).

\footnotetext{
Received for publication 14 May 2008. Accepted for publication 9 July 2008.

We sincerely thank Beijing Municipal Science and Technology Commission for supporting this work through projects "The development of key postharvest technologies of peach fruit" (D0704002040431) and "Study on the key technology for monitoring of agrifood safety" (No. Z07090500550702).

${ }^{1}$ To whom reprint requests should be addressed; e-mail xyfeng@yahoo.cn
}

Application of synthetical fungicides has been the main method for brown rot control; however, there are concerns with the development of fungicide resistance (Conway et al., 2004) and possible harm to human health (Ragsdale and Sisler, 1994). It is therefore necessary to develop alternatives to synthetic chemicals, which can reduce environmental risks and increase consumer confidence.

Alternative disease control methods that have been investigated for peach fruit include heat treatments (Karabulut et al., 2002; Margosan et al., 1997), modified atmosphere (MA) packaging (Karabulut and Baykal, 2004), and biological control (Zhang et al., 2007). Many natural products have been explored in recent years as alternative chemicals to control postharvest fungal rots of fruits and vegetables (Tripathi and Dubey, 2004). Plant extracts from oriental spice plants and herbs such as cinnamon, clove, garlic, thyme, mint, and vanilla showed antimicrobial effects (Ahmad and Prasad, 1995; Damayanti et al., 1996; Kyu Kyu Win et al., 2007; Neri et al., 2007). Phellodendron bark, considered an important Chinese herb, was commonly used in traditional Chinese medicine for various human diseases. The main active component of Phellodendron bark is berberine ( $\mathrm{Li}$ et al., 2006). Berberine from herbs has also been used as a bactericide on apple trees to inhibit apple rot disease and on cucumber to control mildew in laboratory and large-scale field experiments (Dong et al., 2006; Tong et al., 2002).

Induction of resistance to pathogen infection has been indicated as a promising approach for controlling postharvest diseases of fruit (Liu et al., 2005; Qin et al., 2003). Previous studies showed that $\beta$-1,3-glucanases, chitinases, peroxidase, and phenylalanine ammonia-lysase (PAL) were closely related to induction of disease resistance in fruits (Cao et al., 2006; Liu et al., 2005; Qin et al., 2003). The objective of this work was to evaluate the induction of disease resistance in harvested peach fruit after preharvest application of Phellodendron bark extract during the growing season as well as the changes in quality of peach fruit during storage.

\section{Materials and Methods}

Phellodendron bark extract effects on $\mathrm{M}$. fructicola development in vitro. Monilinia fructicola was isolated from decayed peach fruit and maintained on potato dextrose agar (PDA) medium according to method of Liu et al. (2005). Conidia of the pathogens were obtained from 7-d-old PDA cultures incubated at $25{ }^{\circ} \mathrm{C}$. The cultures were flooded with sterile water containing $0.05 \%$ Tween 20 to obtain conidia. The spore suspension was adjusted to $5 \times 10^{4}$ spore $/ \mathrm{mL}$ with a hemacytometer.

Phellodendron bark extracts (PBE), purchased from Tiancheng Drugs \& Bio-engineering Co. (Xian, China), had a minimum berberine content of $5.0 \%$. PBE at concentrations of $0,0.4,0.8,1.6,3.2$, and 6.4 $\mathrm{mg} \cdot \mathrm{mL}^{-1}$ were incorporated into PDA medium, then autoclaved (103.3 $\mathrm{kPa}$ for 15 $\mathrm{min}$ ), and poured into petri plates. A 5-mmdiameter agar disc containing $M$. fructicola from a 7-d-old culture was placed at the center of each plate and incubated for $120 \mathrm{~h}$ at $25{ }^{\circ} \mathrm{C}$. Each treatment contained four replicates of six plates and the experiment was performed twice.

After 120 -h incubation at $25^{\circ} \mathrm{C}$, colony diameter, sporulation, and percentage germination were evaluated (Bautista-Baños et al., 2000). Both sporulation and germination were determined using a microscope with $40 \times$ magnification. Germination was determined by observing the conidia directly with a light microscope. Colony diameter of mycelial growth was measured. Data were expressed as percent of conidia germination or mycelial growth inhibition compared with the control. Each experiment was repeated three times.

Preharvest application of Phellodendron bark extract. The PBE extract fine powders were dissolved in water at $3.5 \mathrm{mg} \cdot \mathrm{mL}^{-1}, 7.0$ 
Table 1. Mycelial growth of the M. fructicola after PBE treatment.

\begin{tabular}{|c|c|c|c|c|c|}
\hline \multirow{2}{*}{$\begin{array}{l}\text { Concn of } \\
\mathrm{PBE} \\
\left(\mathrm{mg} \cdot \mathrm{mL}^{-1}\right)\end{array}$} & \multicolumn{5}{|c|}{$\begin{array}{l}\text { Mycelial growth of } \\
\text { M. fructicola }(\mathrm{mm})\end{array}$} \\
\hline & $24 \mathrm{~h}$ & $48 \mathrm{~h}$ & $72 \mathrm{~h}$ & $96 \mathrm{~h}$ & $120 \mathrm{~h}$ \\
\hline 0.0 & $14.1 \mathrm{a}^{\mathrm{z}}$ & $27.6 \mathrm{a}$ & $39.9 \mathrm{a}$ & $48.8 \mathrm{a}$ & $59.4 \mathrm{a}$ \\
\hline 0.4 & $9.4 \mathrm{~b}$ & $12.8 \mathrm{~b}$ & $16.5 \mathrm{~b}$ & $20.7 \mathrm{~b}$ & $23.6 \mathrm{~b}$ \\
\hline 0.8 & $8.0 \mathrm{c}$ & $10.5 \mathrm{c}$ & $11.6 \mathrm{c}$ & $13.3 \mathrm{c}$ & $13.3 \mathrm{c}$ \\
\hline 1.6 & $0 \mathrm{~d}$ & $0 \mathrm{~d}$ & $0 \mathrm{~d}$ & $0 \mathrm{~d}$ & $0 \mathrm{~d}$ \\
\hline 3.2 & $0 \mathrm{~d}$ & $0 \mathrm{~d}$ & $0 \mathrm{~d}$ & $0 \mathrm{~d}$ & $0 \mathrm{~d}$ \\
\hline
\end{tabular}

${ }^{2}$ Data followed by different letters within the same column are significantly different (Duncan's multiple comparison test, $P<0.05$ ).

$\mathrm{PBE}=$ Phellodendron bark extract.

Table 2. In vitro development of $M$. fructicola with PBE treatment after $10 \mathrm{~h}$ incubation at $25{ }^{\circ} \mathrm{C}$.

\begin{tabular}{lccc}
\hline $\begin{array}{l}\text { PBE } \\
\left(\mathrm{mg} \cdot \mathrm{mL}^{-1}\right)\end{array}$ & $\begin{array}{c}\text { Colony } \\
\text { diam. } \\
(\mathrm{mm})\end{array}$ & $\begin{array}{c}\text { Sporulation } \\
\left(\text { spores } / \mathrm{mL}^{-1}\right)\end{array}$ & $\begin{array}{c}\text { Conidial } \\
\text { germination } \\
(10 \mathrm{~h})(\%)\end{array}$ \\
\hline 0 & $7.1 \mathrm{a}^{\mathrm{z}}$ & $210 \mathrm{a}$ & $83.6 \mathrm{a}$ \\
0.4 & $2.8 \mathrm{~b}$ & $158 \mathrm{a}$ & $32.7 \mathrm{~b}$ \\
0.8 & $1.1 \mathrm{c}$ & $53 \mathrm{~b}$ & $0.0 \mathrm{c}$ \\
1.6 & $0.0 \mathrm{~d}$ & $29 \mathrm{~b}$ & $0.0 \mathrm{c}$ \\
3.2 & $0.0 \mathrm{~d}$ & $0 \mathrm{c}$ & $0.0 \mathrm{c}$ \\
6.4 & $0.0 \mathrm{~d}$ & $0 \mathrm{c}$ & $0.0 \mathrm{c}$ \\
\hline
\end{tabular}

${ }^{\mathrm{z}}$ Data followed by different letters within the same column are significantly different (Duncan's multiple comparison test, $P<0.05$ ).

$\mathrm{PBE}=$ Phellodendron bark extract.

$\mathrm{mg} \cdot \mathrm{mL}^{-1}, 10.5 \mathrm{mg} \cdot \mathrm{mL}^{-1}$, and $21.0 \mathrm{mg} \cdot \mathrm{mL}^{-1}$. Ten-year-old peach trees [Prunus persica (L.) Batsch var. platycarpa (Decne.) L.H. Bailey] cv. Ruipan 4 were used in the field treatments at a commercial orchard in Beijing in 2005, 2006, and 2007. Orchard management was carried out according to regular commercial practice, including application of fungicides that consisted of lime-sulfur over budding twice, Mancozeb $(80 \%$ wettable powder) over flowering twice, and iprodione (Rovral, Bayer CropScience (China) Co., Ltd., Hangzhou, China) applied twice 3 and 8 weeks before harvest.

There were nine trees for each treatment in a randomized block design. Each block comprised three rows (three replicates) with three trees in each row. The four previously mentioned concentration levels of PBE solutions (nine trees per treatment, three replications) were sprayed four times at $\approx 0,30$, 60 , and $90 \mathrm{~d}$ after full bloom stage of trees. Control trees were sprayed with water at the same intervals.

Handling and storage of fruit. Peach fruit were hand-harvested at commercial maturity $(\approx 130 \mathrm{~d}$ after full bloom $)$ and selected for uniformity of size and absence of defects. The fruit were transported to the laboratory immediately and disinfected by immersion for $2 \mathrm{~min}$ in $1 \%$ sodium hypochlorite, rinsed with fresh water, and allowed to air dry at ambient temperature. The fruit $(\approx 600)$ from each treatment were randomly divided into two groups. The first group, which consisted of 500 fruit, was stored at $0{ }^{\circ} \mathrm{C}$ with MA package for the storage experiment and qual-
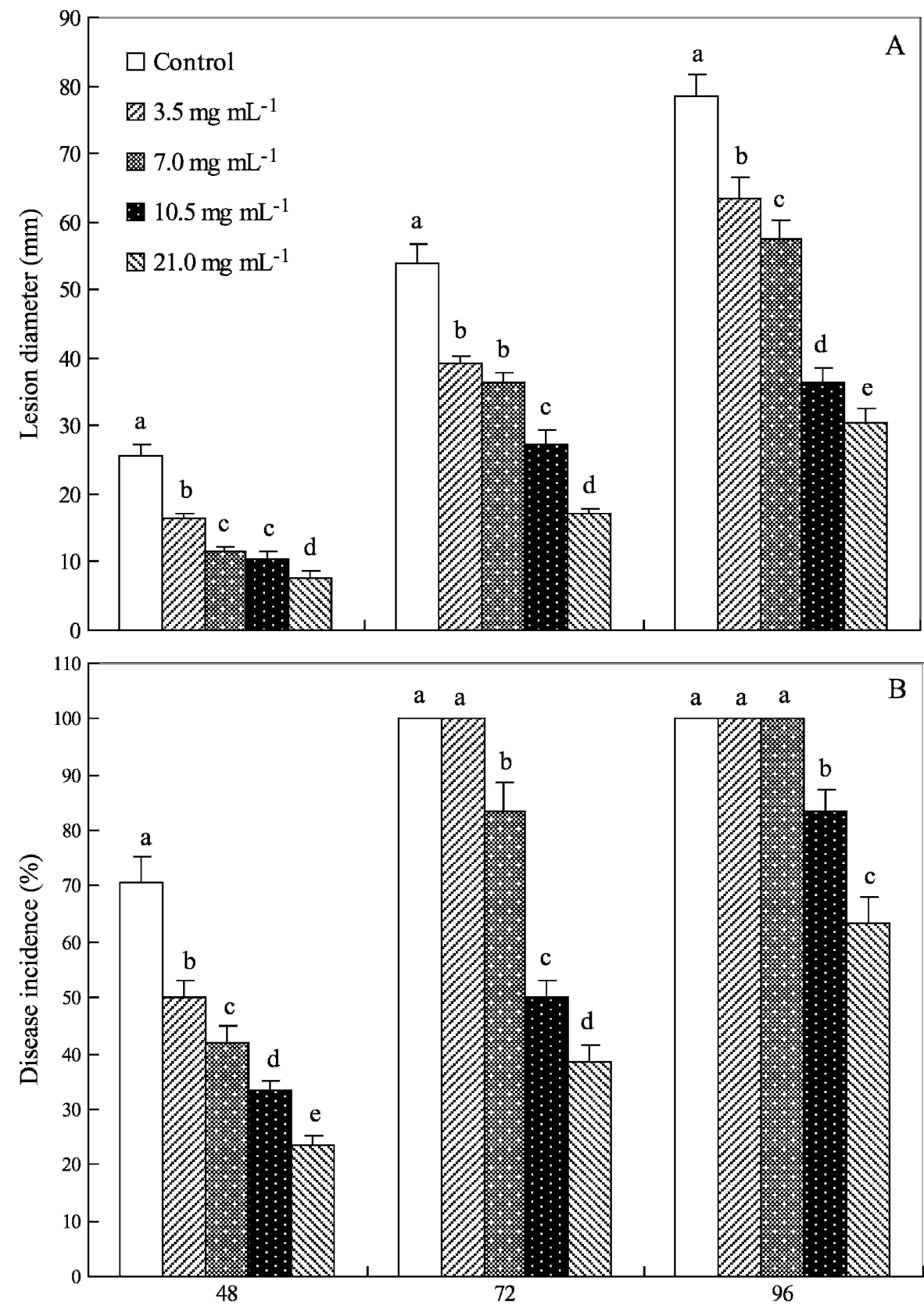

Hours after inoculation

Fig. 1. Lesion diameter (A) and disease incidence (B) in Phellodendron bark extract (PBE)-treated peach fruit inoculated with Monilinia fructicola after harvest. Peach trees were sprayed with 3.5, 7.0, 10.5, or $21.0 \mathrm{mg} \cdot \mathrm{mL}^{-1} \mathrm{PBE}$ or water (control) at $0,30,60$, and $90 \mathrm{~d}$ after full bloom. The harvested fruit were inoculated with $15 \mu \mathrm{L}$ of the conidial suspension of $M$. fruncticola $\left(5 \times 10^{4}\right.$ spores $\left./ \mathrm{mL}\right)$ and incubated at $25{ }^{\circ} \mathrm{C}$ and $95 \%$ relative humidity for disease development. Bars with the same letter are not significantly different $(P>0.05)$. Vertical lines represent SDS of the means $(\mathrm{n}=3)$.

ity and enzyme analysis, whereas the second group of 100 fruit was used in artificial inoculation experiments at ambient temperature just after harvest.

Inoculation experiment. All fruit for inoculation were surface-sterilized with $70 \%$ ethanol and then wounded ( $3 \mathrm{~mm}$ diameter $\times$ $4 \mathrm{~mm}$ deep) with a sterile needle at two points around the equator of each fruit. Spore suspensions $\left(15 \mu \mathrm{L}, 5 \times 10^{4}\right.$ spores $\left./ \mathrm{mL}\right)$ of $M$. fructicola were pipetted into each wounded site. Inoculated fruit were placed in plastic trays and stored at $25{ }^{\circ} \mathrm{C}, 95 \%$ to $100 \%$ relative humidity. Disease incidence (the percentage of fruit with visible disease development) and lesion diameter were measured daily after inoculation for $4 \mathrm{~d}$. Each treatment was applied to three replicates of 30 peaches and the experiment was performed in 2005 , 2006, and 2007.

Phellodendron bark extract effects on decay and quality during storage. Disease incidence of fruit was determined after 8 weeks of storage at $0{ }^{\circ} \mathrm{C}$ and an additional $3 \mathrm{~d}$ at ambient temperature in 2005, 2006, and 2007. Fruit were considered decayed when 
visible decay lesion was observed. Disease incidence of the fruit was calculated as decayed fruit/total fruit. Sixty fruit of each treatment were evaluated in this experiment every year.

Fruit firmness was tested by a fruit penetrometer (FT-327; Facchini, Alfonsine, Italy) with a 7.9-mm-diameter tip and expressed as Newtons. Total soluble solids content was measured on a few drops of juice with a digital refractometer (PAL-1, Atago, Japan). Juice samples for soluble solids content were obtained from 20 discs of flesh (two discs per fruit on opposite regions) from 10 fruit. To measure titratable acidity, $100 \mathrm{~g}$ flesh tissue from 10 fruit was homogenized with $100 \mathrm{~mL}$ distilled water and then $50 \mathrm{~g}$ of homogenates was taken to constant volume to $250 \mathrm{~mL}$ with distilled water. The samples were heated in a boiling water bath for $30 \mathrm{~min}$ before adjusting volume to $250 \mathrm{~mL}$ and then filtered. The filtrate $(50 \mathrm{~mL})$ was titrated with $0.1 \mathrm{M}$ $\mathrm{NaOH}$ to a final $\mathrm{pH}$ of 8.1 using an automatic titrator (794 Basic Titrino, Metrohm, Switzerland). Titratable acidity was expressed as grams of malic acid per $100 \mathrm{~g}$ of fresh weight. All treatments were run with three replications of 10 fruits each.

Flesh browning was assessed by measuring the flesh browning area after fruit were halved along the equatorial section and was calculated on a scale from 1 to 3 . Browning of individual fruit was scored on browning scale of: $0=$ no browning, $1=$ browning area was less than $25 \%, 2=$ browning area was $25 \%$ to $75 \%, 3=$ browning area was larger than $75 \%$. Thirty fruit in each treatment were evaluated. Browning index was then calculated using the following equation:

Browning index

$$
=\frac{\sum \text { (Browning scale } \times \text { Number }}{\text { of corresponding of fruit })}
$$

Phellodendron bark extract effects on fruit enzymatic activities. For polyphenoloxidase activity assay, $5 \mathrm{~g}$ of the sample tissue were thoroughly homogenized with $10 \mathrm{~mL}$ $0.2 \mathrm{M}$ phosphate buffer ( $\mathrm{pH} 6.4$ ) and centrifuged at $10,000 \times g$ at $4{ }^{\circ} \mathrm{C}$ for $20 \mathrm{~min}$. Then supernatant $(1.5 \mathrm{~mL})$ was mixed with $3 \mathrm{~mL}$ of $0.05 \mathrm{~m}$ phosphate buffer $(\mathrm{pH} 7.0)$ and $1 \mathrm{~mL}$ of $0.5 \mathrm{M}$ catechol. After incubating at $24^{\circ} \mathrm{C}$ for $30 \mathrm{~min}$, the absorbance at $420 \mathrm{~nm}$ of the reaction mixture was measured. The polyphenoloxidase activity was expressed as the change in the absorbance at $420 \mathrm{~nm}$ per gram of fresh weight per minute $\left(\Delta \mathrm{OD}_{420} \mathrm{~g}^{-1} \cdot \mathrm{min}^{-1}\right.$ FW).

For peroxidase activity assay, sampled tissues $(5.0 \mathrm{~g})$ were homogenized on ice with $5 \mathrm{~mL}$ of $100 \mathrm{~mm}$ sodium acetate buffer $(\mathrm{pH}$ 5.5) containing $1 \mathrm{~mm}$ polyethyleneglycol, $1 \%$ (v/v) Triton-100, 8\% (v/v) polyvinylpolypyrrolidine, and $1 \mathrm{~mm}$ phenyl-methyl-sulphonyl fluorides. The homogenate was centrifuged at $10,000 \times g$ for $20 \mathrm{~min}$ at $4{ }^{\circ} \mathrm{C}$. Peroxidase activity of supernatants was assayed accord- ing to Lurie et al. (1997) and expressed as $\Delta \mathrm{OD}_{470} \mathrm{~g}^{-1}$ fresh weight $/ \mathrm{min}^{-1}$.

For PAL activity assay, sampled tissues $(5.0 \mathrm{~g})$ were homogenized on ice with $5 \mathrm{~mL}$ of $100 \mathrm{~mm}$ sodium borate buffer $(\mathrm{pH} 8.8)$ containing $5 \mathrm{~mm} \beta$-mercaptoethanol, $2 \mathrm{~mm}$ ethylene diaminetetraacetic acid, and 4\% (w/v) polyvinyl pyrrolidine. The homogenate was centrifuged as described previously. PAL activity was determined according to Assis et al. (2001). The unit of PAL activity was defined as the change in absorbance of 0.01 per gram of fresh weight per hour.

Chitinase was determined according to the method of Cao et al. (2006). Chitinase activities were expressed as unit per milligram fresh weight. $\beta$-1,3-glucanase activity was assayed according to Abeles and Forrence (1979) with some modifications. Fifty microliters of the enzymatic extract was incubated with $50 \mu \mathrm{L}$ of $4 \%(\mathrm{w} / \mathrm{v})$ laminarin (Sigma, St. Louis, MO) at $37{ }^{\circ} \mathrm{C}$ for $30 \mathrm{~min}$. The reacted mixture was added with $400 \mu \mathrm{L}$ of dinitrosalicylate and boiled for $5 \mathrm{~min}$. After cooling, absorbance of the solution at $500 \mathrm{~nm}$ was measured. The $\beta$-1,3-glucanase activity was expressed as units per milligram fresh weight, where one unit was defined as the reducing sugar equivalent to $1 \times 10^{-6} \mathrm{~mol}$ of glucose produced per second under the assay conditions.

Statistical analysis. Data were collected and analyzed by one-way analysis of variance with statistical software of the SPSS 11.0 for windows (SPSS, Chicago). Means separation was performed by Duncan's multiple comparison procedure, and differences at the $5 \%$ level were considered significant.

\section{Results}

Phellodendron bark extract effects on $\mathrm{M}$. fructicola development in vitro. PBE had a direct inhibitory effect on mycelial growth of $M$. fructicola in vitro. The mycelial growth of M. fructicola on PDA significantly decreased with the increase of PBE concentration (Table 1). After $120 \mathrm{~h}$ of incubation at $25^{\circ} \mathrm{C}$, $\mathrm{PBE}$ at $0.4 \mathrm{mg} \cdot \mathrm{mL}^{-1}$ significantly inhibited the growth of the fungi. PBE at $1.6 \mathrm{mg} \cdot \mathrm{mL}^{-1}$ completely inhibited the mycelial growth.

As shown in Table 2, PBE treatment reduced the development of $M$. fructicola compared with the control. Sporulation was completely inhibited with $3.2 \mathrm{mg} \cdot \mathrm{mL}^{-1} \mathrm{PBE}$. Monilinia fructicola could not grow in medium containing $1.6 \mathrm{mg} \cdot \mathrm{mL}^{-1} \mathrm{PBE}$. The highest germination was observed in control, whereas M. fructicola spores could not germinate in medium containing $0.8 \mathrm{mg} \cdot \mathrm{mL}^{-1}$ PBE (Table 2).

Phellodendron bark extract effects on disease incidence. Preharvest application of PBE significantly reduced postharvest decay of peach fruit inoculated with $M$. fructicola, and the efficacy was enhanced with the increase of its concentration (Fig. 1). For example, after $72 \mathrm{~h}$ of incubation at $25^{\circ} \mathrm{C}$, the lesion diameter of fruit treated with $\mathrm{PBE}$ at $21.0 \mathrm{mg} \cdot \mathrm{mL}^{-1}$ was only $17.3 \mathrm{~mm}$ when the lesion diameter in control fruit was $51.4 \mathrm{~mm}$. The disease incidence on fruit treated with $21.0 \mathrm{mg} \cdot \mathrm{mL}^{-1} \mathrm{PBE}$ was $61.7 \%$ lower than that in control (Fig. 1B).

Disease incidence caused by $M$. fructicola was not severe during the first 8 weeks of storage (Fig. 2A) but rapidly increased during the additional $3 \mathrm{~d}$ at $25^{\circ} \mathrm{C}$ (Fig. 2B). Preharvest $21 \mathrm{mg} \cdot \mathrm{mL}^{-1}$ PBE application effectively reduced disease incidence of peach fruit in experiments of each season from 2005 to 2007. In addition, the control/ PBE ratio of disease incidence of fruit after storage plus $3 \mathrm{~d}$ at $25^{\circ} \mathrm{C}$ was $1.6,2.3$, and 3.2 in 2005,2006 , and 2007 , respectively, indicating that the effectiveness of PBE increased over the years. Similar results were also observed during storage without the additional $3 \mathrm{~d}$ at $25^{\circ} \mathrm{C}$.

Phellodendron bark extract effects on fruit quality. Softening was significantly $(P<0.05)$ inhibited by PBE sprays before harvest (Fig. 3A). The firmness of fruit treated with $21 \mathrm{mg} \cdot \mathrm{mL}^{-1} \mathrm{PBE}$ was $28.0 \%$ and $25.4 \%$ higher $(P<0.05)$ than that of the control after the second and sixth weeks of storage, respectively.

During storage, soluble solids content in control was slightly higher than that of PBEtreated fruit and then decreased rapidly after 6 weeks of storage (Fig. 3B). However, soluble solids content in PBE-treated fruit was maintained after 2 weeks of storage. Titratable acidity content in PBE-treated fruit was higher than that of controls, which decreased rapidly during storage (Fig. 3C).

The occurrence of flesh browning, expressed as browning index, was inhibited by PBE. For example, browning index of PBEtreated fruit was $61.3 \%$ lower than that of controls after 8 weeks of storage (Fig. 3D).

Phellodendron bark extract effects on fruit enzymatic activities. Peroxidase activity of both treated and nontreated fruit increased at the beginning of storage, reaching a peak at the first week and then decreased rapidly (Fig. 4A). However, peroxidase activity in fruit treated with $21 \mathrm{mg} \cdot \mathrm{mL}^{-1} \mathrm{PBE}$ was higher than the control during most of the storage period.

The PAL activity of peach fruit was dramatically induced by preharvest PBE treatment during the entire 8-week storage (Fig. 4B). PAL activity in samples treated with $21 \mathrm{mg} \cdot \mathrm{mL}^{-1}$ was 1.75 - and 2.65 -fold higher than the controls at the fourth and eighth weeks of storage, respectively (Fig. 4B). Similar induction of chitinase and $\beta-1,3-$ glucanase activities by preharvest PBE application were also observed in fruit during storage compared with the control (Fig. 4C-D).

The activity of polyphenoloxidase reached a peak after 1 week of storage in all treatments and then rapidly decreased. Polyphenoloxidase activity in fruit preharvest treated with PBE was markedly decreased at the beginning of storage at $0{ }^{\circ} \mathrm{C}$, which was $15.1 \%$ and $13.2 \%$ lower than that of controls 

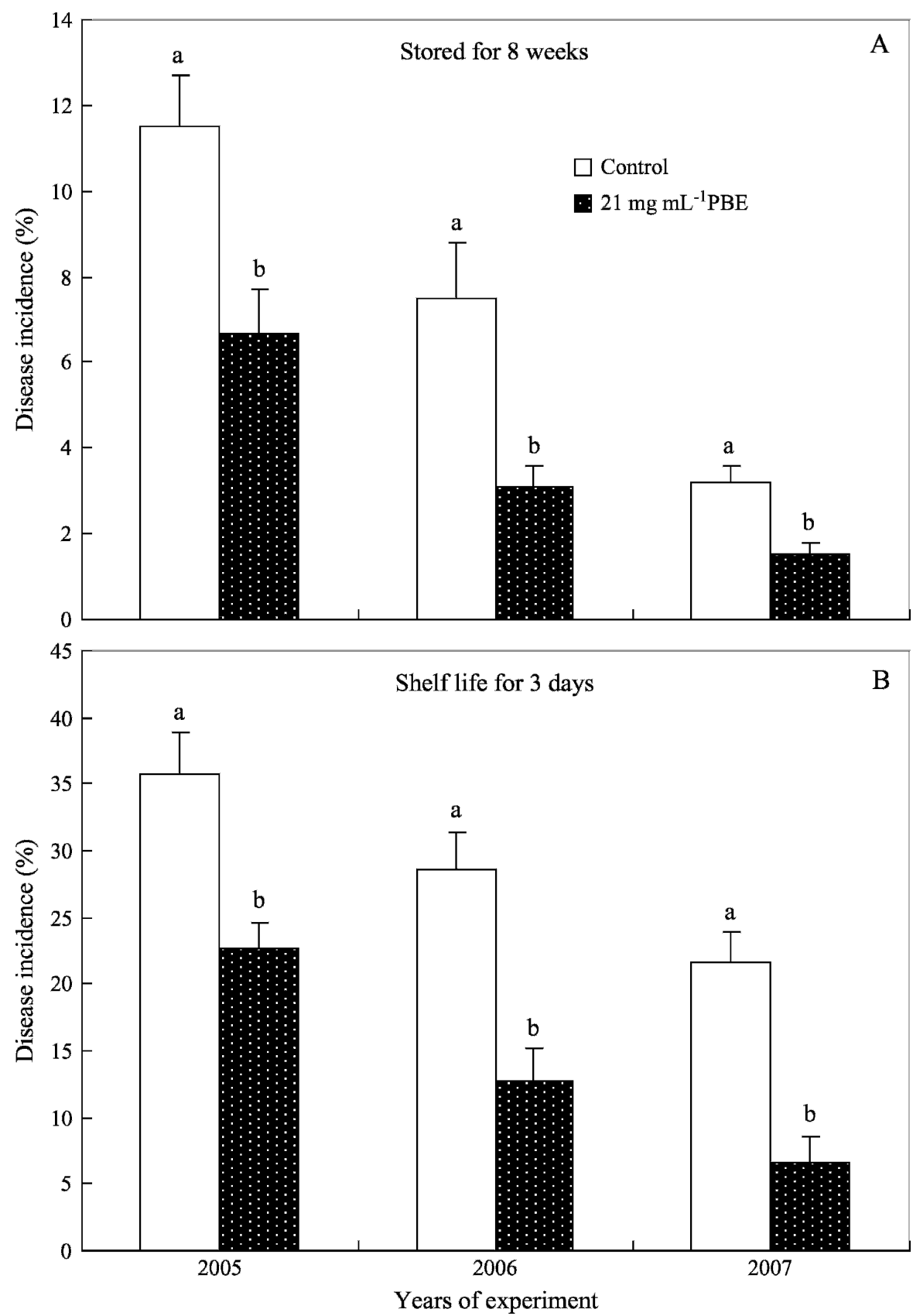

Fig. 2. Postharvest disease development of peach fruit treated with Phellodendron bark extract (PBE) during storage and shelf life. Peach trees were sprayed with $21.0 \mathrm{mg} \cdot \mathrm{mL}^{-1} \mathrm{PBE}$ or water (control) four times at $0,30,60$, and $90 \mathrm{~d}$ after full bloom. The harvested fruit were stored for 8 weeks of storage at $0{ }^{\circ} \mathrm{C}(\mathbf{A})$ and an additional $3 \mathrm{~d}$ at $25^{\circ} \mathrm{C}(\mathbf{B})$ in 2005,2006 , and 2007. Bars with the same letters are not significantly different $(P>0.05)$. Vertical lines represent sDs of the means $(\mathrm{n}=3)$.

at the second and sixth weeks of storage, respectively (Fig. 5).

\section{Discussion}

In recent years, plant extracts have been specially reported to have antimicrobial activity against a wide range of fungi (Doubrava et al., 1998; Kumar and Tripathi, 1991; Kyu Kyu Win et al., 2007). Our results showed that preharvest application of PBE was effective for inhibiting pathogen growth as well as inducing disease resistance in
2004). Spore formation and germination, mycelial growth in vitro, and infection of plants could be inhibited by plant extracts (Kyu Kyu Win et al., 2007; Lee et al., 2007; Plaza et al., 2004). Similar results were observed in the present study. The direct inhibition of the growth of $M$. fructicola by PBE could be attributed to a large amount of bioactive substances present in this extract. In our study, berberine, the chemical component of $\mathrm{PBE}(\approx 5 \%)$, may result in the positive antimicrobial effect. Further study is needed to clarify which other substances in PBE may have an antimicrobial effect against fungal pathogens.

In addition to the direct inhibition of fungal growth as described previously, the indirect induction of defense response in fruit may work together to retard the development of pathogen. Previous studies showed that fruit could be protected from fungal pathogen invasion mainly by the activation of a highly coordinated biochemical and structural defense system (Schroder et al., 1992). The present study showed that activities of enzymes, including peroxidase, PAL, chitinase, and $\beta$-1,3-glucanase, in peach fruit were all induced by PBE sprays on the trees. Similar phenomena were also observed in relevant studies on other plants (Liu et al., 2005; Yao and Tian, 2005). Peroxidase, PAL, chitinase, and $\beta$-1,3-glucanase have been suggested as being involved in plant defense responses against fungal infection (Lurie et al., 1997; MauchMani and Slusarenko, 1996; Qin et al., 2003). Peroxidase catalyzes the last step of lignin biosynthesis, whereas PAL is the first enzyme of the phenylpropanoid pathway and is involved in the biosyntheses of phenolics, phytoalexins, and lignins (Mauch-Mani and Slusarenko, 1996; Pellegrini et al., 1994). Meanwhile, $\beta$-1,3-glucanase in combination with chitinase was shown to degrade the cell wall of fungi and bacteria (Schneider and Ullrich, 1994). Lower fruit decay in PBEtreated fruit may be related with the stimulation of these enzymes. PBE sprays may activate the development of systemic acquired resistance by inducing these pathogenesis-related proteins and resulting in disease resistance against fungal attack in peach fruit, and this induced resistance may continue.

In our study, firmness and titratable acidity of peach fruit treated with PBE were higher than those of control (Fig. 4). Lower browning incidence of PBE-treated fruit may be attributed to the inhibition of polyphenoloxidase activity by PBE treatment (Brandelli et al., 2005; Cano et al., 1997). Overall preharvest spray of PBE could delay the disease development and senescence of peaches and maintain the quality of peach fruit during cold storage. PBE is edible and safe for humans with a high $\operatorname{LD}_{50}(6810$ $\mathrm{mg} \cdot \mathrm{kg}^{-1}$ body weight, data not shown) and has been used in human medicine. The results obtained in this study showed that PBE has a potential in management of postharvest diseases of peach. 

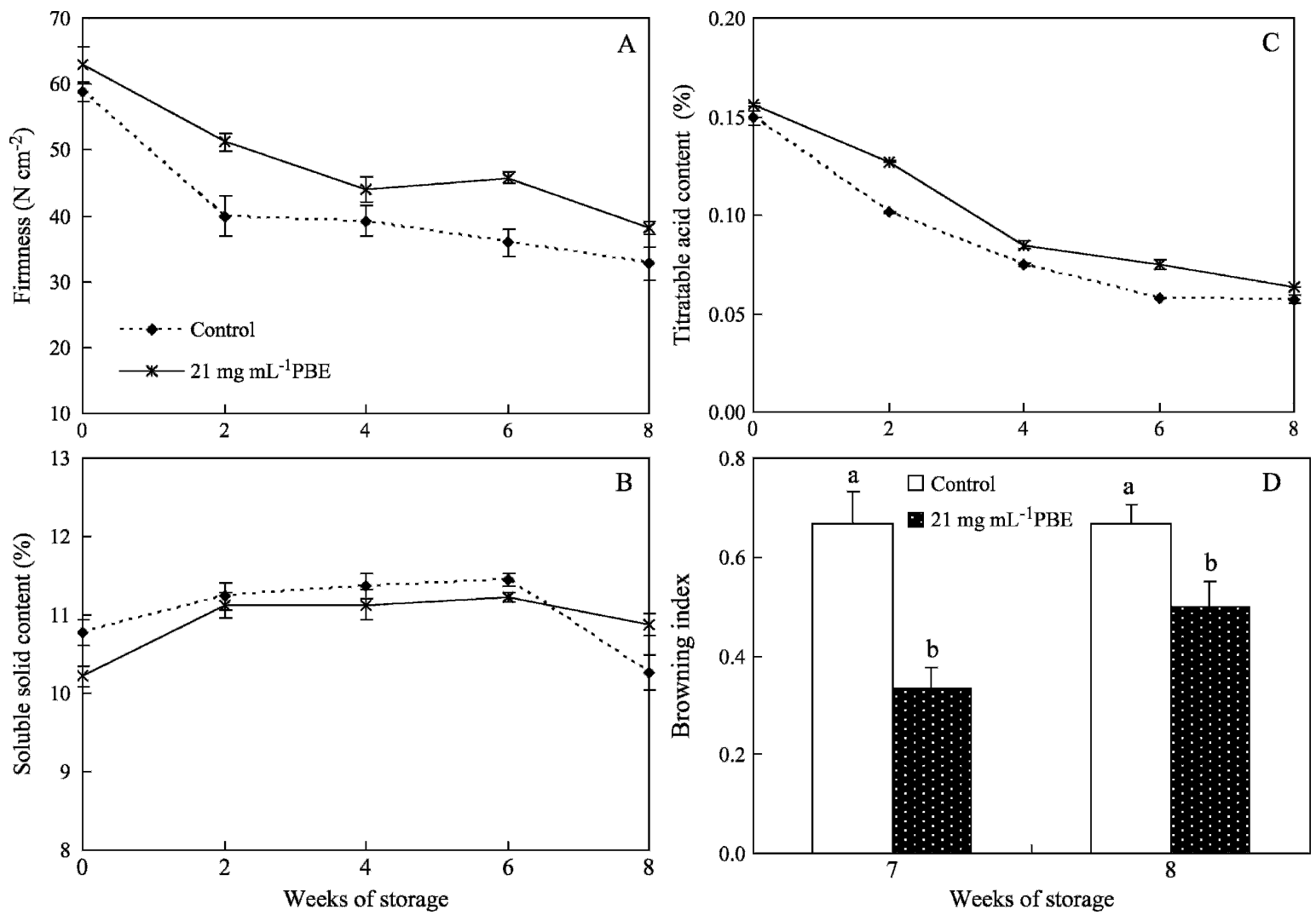

Fig. 3. Postharvest qualities of peach fruit treated with Phellodendron bark extract (PBE) during storage. Peach trees were sprayed with $21.0 \mathrm{mg} \cdot \mathrm{mL}^{-1} \mathrm{PBE}$ or water (control) four times at $0,30,60$, and $90 \mathrm{~d}$ after full bloom. The harvested fruit were stored at $0{ }^{\circ} \mathrm{C}$ for 8 weeks. Firmness (A), titratable acidity (B), soluble solids content (C), and flesh browning (D) was determined. Each point or column represents the mean of three replicates. Vertical lines represent sDs of the means $(\mathrm{n}=3)$.
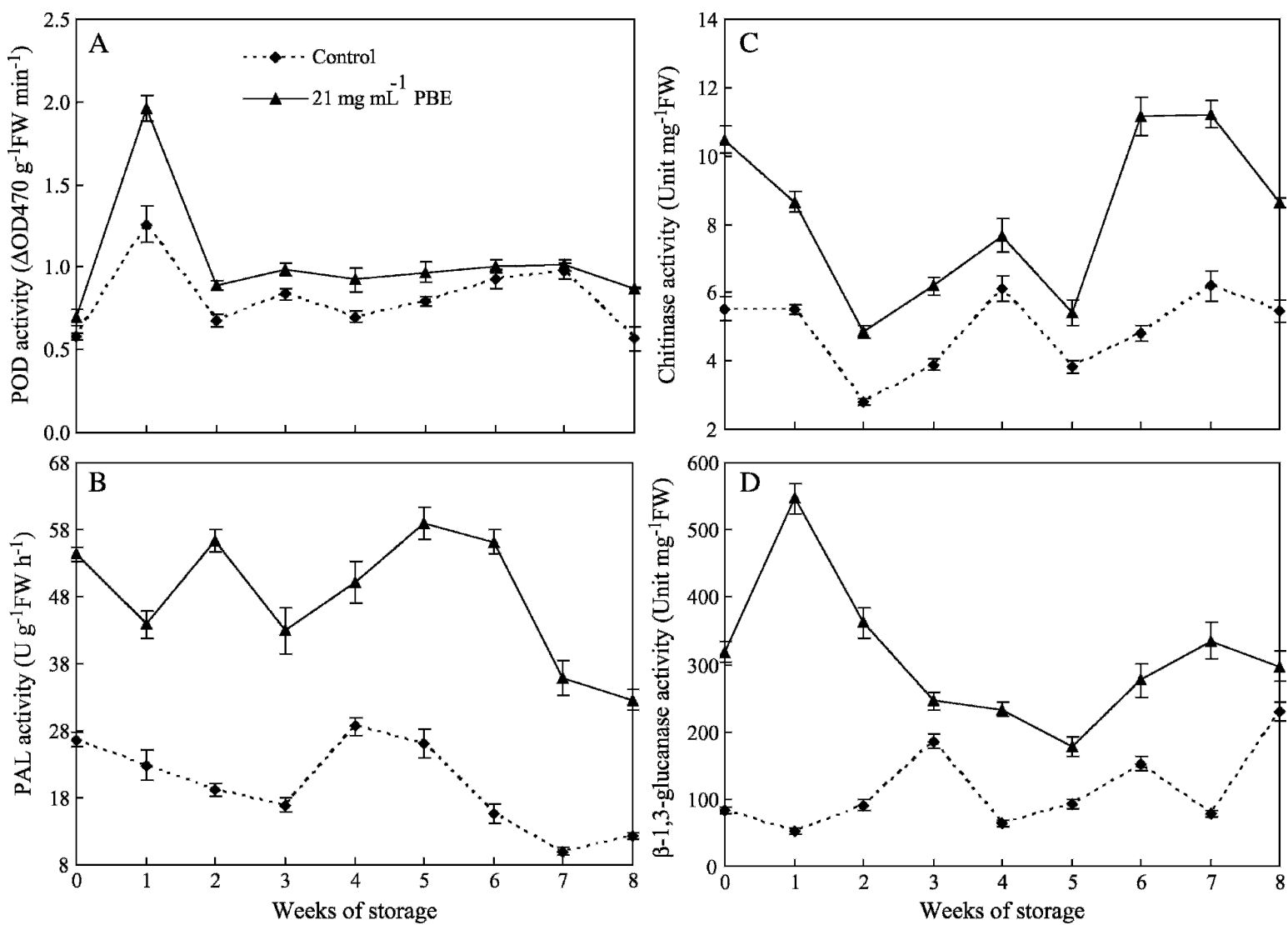

Fig. 4. Peroxidase (A), phenylalanine ammonia-lysase (B), chitinase (C), and $\beta$-1,3-glucanase $(\mathbf{D})$ activities of peach fruit treated with Phellodendron bark extract (PBE) during storage. Peach trees were sprayed with $21.0 \mathrm{mg} \cdot \mathrm{mL}^{-1} \mathrm{PBE}$ or water (control) four times at $0,30,60$, and $90 \mathrm{~d}$ after full bloom. The harvested fruit were stored for 8 weeks at $0{ }^{\circ} \mathrm{C}$. Enzyme activities were analyzed every week. Vertical bars represent sDs of the means $(\mathrm{n}=3)$. 


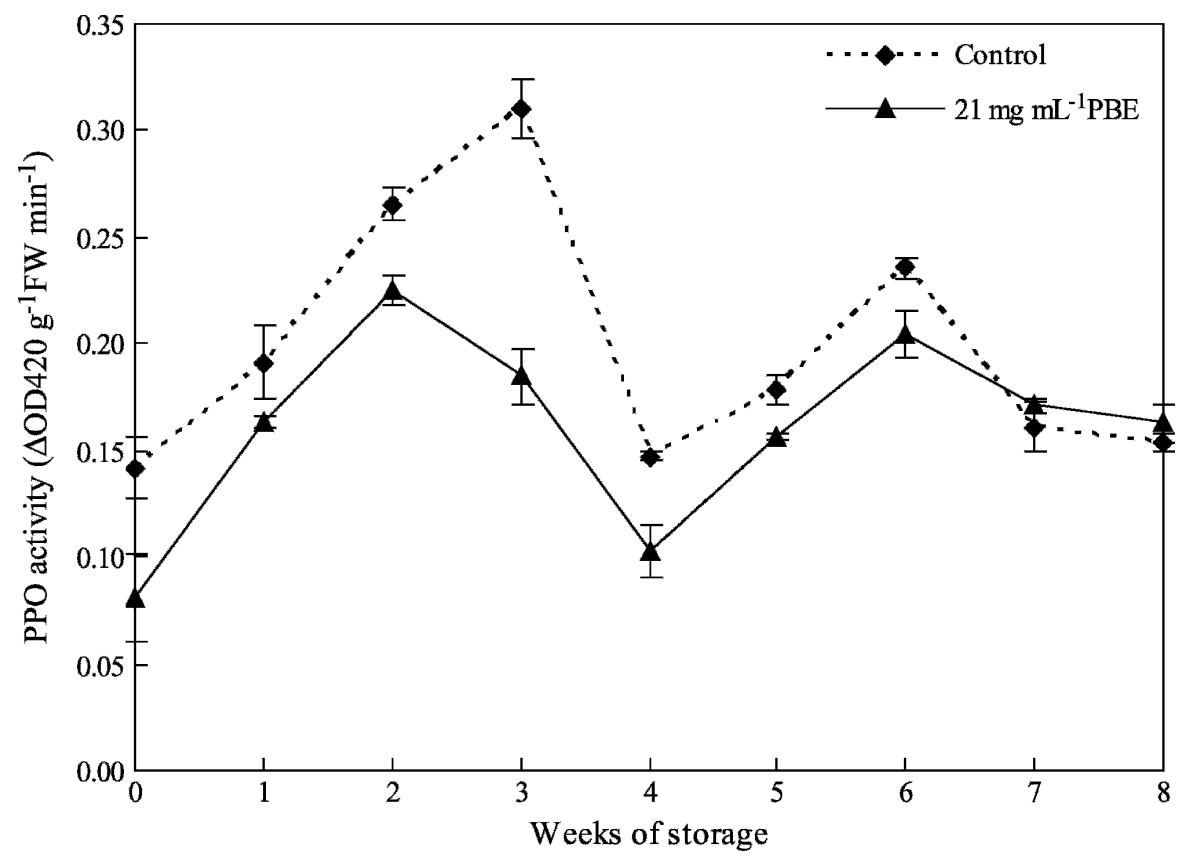

Fig. 5. Polyphenoloxidase (PPO) activity of peach fruit treated with Phellodendron bark extract (PBE) during storage. Peach trees were sprayed with $21.0 \mathrm{mg} \cdot \mathrm{mL}^{-1} \mathrm{PBE}$ or water (control) four times at 0,30 , 60 , and $90 \mathrm{~d}$ after full bloom. The harvested fruit were stored for 8 weeks at $0{ }^{\circ} \mathrm{C}$. PPO activity was analyzed every week. Vertical bars represent SDS of the means $(n=3)$.

\section{Literature Cited}

Abeles, F.B. and L.E. Forrence. 1979. Temporal and hormonal control of $\beta$-1,3-glucanase in Phaseolus vulgaris L. Plant Physiol. 45:395400.

Ahmad, S.K. and J.S. Prasad. 1995. Efficacy of foliar extracts against pre- and post-harvest diseases of sponge-gourde fruits. Lett. Appl. Microbiol. 21:373-375.

Assis, J.S., R. Maldonado, T. Munoz, M.I. Escribano, and C. Merodio. 2001. Effect of high carbon dioxide concentration on PAL activity and phenolic contents in ripening cherimoya fruit. Postharvest Biol. Technol. 23:33-39.

Bautista-Baños, S., M. Hernández-López, J.C. Díaz-Pírez, and C.F. Cano-Ochoa. 2000. Evaluation of the fungicidal properties of plant extracts to reduce Rhizopus stolonifer of "ciruela' (Spondias purpurea L.) during storage. Postharvest Biol. Technol. 18:67-73.

Brandelli, A., H. Carlos, and G.L. Lopes. 2005. Polyphenoloxidase activity, browning potential and phenolic content of peaches during postharvest ripening. J. Food Biochem. 29:624637.

Cano, M.P., B. de Ancos, M. Gloria Lobo, and M. Santos. 1997. Improvement of frozen banana (Musa cavendishii, cv. Enana) colour by blanching: Relationship between browning, phenols and polyphenol oxidase and peroxidase activities. Eur. Food Res. Technol. 204:60-65.

Cao, J.K., K.F. Zeng, and W.B. Jiang. 2006. Enhancement of postharvest disease resistance in Ya li pear (Pyrus bretschneideri) fruit by salicylic acid sprays on the trees during fruit growth. Eur. J. Plant Pathol. 114:363370.

Conway, W. 1987. Effects of preharvest and postharvest calcium treatments of peaches on decay caused by Monilinia fructicola. HortScience 32:820-823.

Conway, W.S., B. Leverentz, W.J. Janisiewicz, A.B. Blodgett, R.A. Saftner, and M.J. Camp.
Kyu Kyu Win, N., P. Jitareerat, S. Kanlayanarat, and S. Sangchote. 2007. Effect of cinnamon extract, chitosan coating, hot water treatment and their combinations on crown rot disease and quality of banana fruit. Postharvest Biol. Technol. 45:333-340.

Lee, S.H., K.S. Chang, M.S. Su, Y.S. Huang, and H.D. Jang. 2007. Effects of some Chinese medicinal plant extracts on five different fungi. Food Contr. 18:1547-1554.

Li, C.Y., H.J. Lu, C.H. Lin, and T.S. Wu. 2006. A rapid and simple determination of protoberberine alkaloids in Phellodedron bark by $1 \mathrm{H}$ NMR and its application for quality control of commercial traditional Chinese medicine prescriptions. J. Pharm. Biomed. Anal. 40:173178.

Lichou, J.O., X. De Eribe, and J. Usall. 2005. Biological control of postharvest brown rot (Monilinia spp.) of peaches by field applications of Epicoccum nigrum. Biol. Control 32: 305-310.

Liu, H.X., W.B. Jiang, Y. Bi, and Y.B. Luo. 2005. Postharvest BTH treatment induces resistance of peach (Prunus persica L. cv Jiubao) fruit to infection by Penicillium expansum and enhances activity of fruit defense mechanism. Postharvest Biol. Technol. 35:263269.

Lurie, S., E. Fallik, A. Handros, and R. Shapira. 1997. The possible involvement of peroxidase in resistance to Botrytis cinerea in heat-treated tomato fruit. Physiol. Mol. Plant Pathol. 50:141-149.

Margosan, D.A., J.L. Smilanick, G.F. Simmons, and D.J. Henson. 1997. Combination of hot water and ethanol to control postharvest decay of peaches and nectarines. Plant Dis. 81:14051409.

Mauch-Mani, B. and A.J. Slusarenko. 1996. Production of salicylic acid precursors is a major function of phenylalanine ammonialyase in the resistance of arabidopsis to Peronospora parasitica. Plant Cell 8:203-212.

Dong, Z.G., K.J. Liu, G. Yang, X. Ren, Y.K. Jin, and C.Z. Hui. 2006. The preliminary study of effect of berberine complex on rot disease of apple tree fruits. Northern Fruits. 3:14 15 .

Doubrava, N.S., R.A. Dean, and J. Kuc. 1998 Induction of systemic resistance to anthracnose caused by Coletotrichum legenarium in cucumber by oxalate and extract from spinach and rhubarb leaves. Physiol. Mol. Plant Pathol. 33:69-79.

Elmer, P.A.G., T.M. Spiers, and P.N. Wood. 2007. Effects of pre-harvest foliar calcium sprays on fruit calcium levels and brown rot of peaches. Crop Prot. 26:11-18.

Hong, C.X., T.J. Michailides, and B.A. Holtz. 1998. Effects of wounding, inoculum density, and biological control agents on postharvest brown rot of stone fruits. Plant Dis. 82:1210 1216.

Karabulut, O.A. and N. Baykal. 2004. Integrated control of postharvest diseases of peaches with a yeast antagonist, hot water and modified atmosphere packaging. Crop Prot. 23:431435.

Karabulut, O.A., L. Cohen, B. Wiess, A. Daus, S. Lurie, and S. Droby. 2002. Control of brown rot and blue mold of peach and nectarine by short hot water brushing and yeast antagonists. Postharvest Biol. Technol. 24: $103-111$.

Kumar, A. and S.C. Tripathi. 1991. Evaluation of the leaf juice of some higher plants for their toxicity against soil borne pathogens. Plant Soil 132:297-301
Neri, F., M. Mari, S. Brigati, and P. Bertolini. 2007. Fungicidal activity of plant volatile compounds for controlling Monilinia laxa in the stone fruit. Plant Dis. 91:30-35.

Pellegrini, L., O. Rohfritsch, B. Fritig, and M. Legrand. 1994. Phenylalanine ammonia-lyase in tobacco. Plant Physiol. 106:877-886.

Plaza, P., R. Torres, J. Usall, N. Lamarca, and I. Viñas. 2004. Evaluation of the potential of commercial post-harvest application of essential oils to control citrus decay. J. Hort. Sci. Biotechnol. 79:935-940.

Qin, G.Z., S.P. Tian, Y. Xu, and K.W. Ya. 2003. Enhancement of biocontrol efficacy of antagonistic yeasts by salicylic acid in sweet cherry fruit. Physiol. Mol. Plant Pathol. 62:147-154

Ragsdale, N.N. and H.D. Sisler. 1994. Social and political implications of managing plant diseases with decreased availability of fungicides in the United States. Annu. Rev. Phytopathol. 32:545-557.

Schneider, S. and W. Ullrich. 1994. Differential induction of resistance and enhanced enzyme activities in cucumber and tobacco caused by treatment with various abiotic and biotic inducers. Physiol. Mol. Plant Pathol. 45:291304.

Schroder, M., K. Hahlbrock, and E. Kombrink. 1992. Temporal and spatial patterns of $\beta-1$, 3 -glucanase and chitinase induction in potato leaves infected by Phytophthora infestans. Plant J. 2:161-172. 
Thangavelu, R., P. Sundararaju, and S. Sathiamoorthy. 2004. Management of anthracnose disease of banana caused by Colletotrichum musae using plant extracts. J. Hort. Sci. Biotechnol. 79:664-668.

Tong, S.M., X.J. Li, and X.Q. Yang. 2002. Investigation of $0.6 \%$ radix sophorae FlavescentisBerberine bactericide and its application on apple tree. Agro-environmental Production. 21:67-69.

Tripathi, P. and N.K. Dubey. 2004. Exploitation of natural products as an alternative strategy to control postharvest fungal rotting of fruit and vegetables. Postharvest Biol. Technol. 32:235-245.

Yao, H.J. and S.P. Tian. 2005. Effects of pre- and post-harvest application of salicylic acid or methyl jasmonate on inducing disease resistance of sweet cherry fruit in storage. Postharvest Biol. Technol. 35:253262.

Zhang, H.Y., X.D. Zheng, and T. Yu. 2007. Biological control of postharvest diseases of peach with Cryptococcus Laurentii. Food Contr. 18:287-291. 